www.jmscr.igmpublication.org

Impact Factor 5.84

Index Copernicus Value: 83.27

ISSN (e)-2347-176x ISSN (p) 2455-0450

crossref DOI: _https://dx.doi.org/10.18535/jmscr/v5i4.230

Journal Of Medical Science And Clinical Research

\title{
Tuberculous Otitis Media: A Prospective Study
}

Authors

\author{
Dr Sudhir S Kadam ${ }^{1}$, Dr Geeta S Kadam ${ }^{2}$, Dr Jaydeep Pol ${ }^{3}$, Dr Sunil Khot ${ }^{4}$ \\ ${ }^{1}$ Associate Professor, Department of ENT, Government Medical College Miraj, Maharashrta \\ ${ }^{2}$ Consulting Pathologist, Yashashri ENT hospital, Miraj, Maharashtra \\ ${ }^{3}$ Consulting Pathologist, Deep Laboratory, Miraj \\ ${ }^{4}$ Assistant Professor, Department of ENT, Government Medical College Miraj, Maharashrta \\ Corresponding Author \\ Dr Geeta S Kadam \\ Consulting Pathologist, Yashashri ENT hospital, Miraj, Maharashtra
}

\begin{abstract}
Abstarct
Background: Tuberculosis is a chronic granulomatous disease that can affect any part of the body. Being endemic in India tuberculosis must be included in the differential diagnosis of chronic otitis media not responding to usual antibiotics. The diagnosis is more likely in the setting of patients on immunosuppressive therapy, patients receiving steroids or patients with past or family history of tuberculosis. In many cases tuberculous otitis media is not diagnosed mainly because it is often not suspected. We conducted this disease to study the tubercular otitis media, its clinical features, examination findings, intra-operative appearance and for knowing up to what extent an early diagnosis and intervention could restore normal hearing in these patients.
\end{abstract}

Aims and Objectives: To study the patients of tubercular otitis media and their clinical presentations, clinical examination, intraoperative findings and incidence of deafness in patients having tubercular otitis media.

Material and Methods: This was a multi-centric prospective cohort study comprising of 60 patients who attended ENT department of a medical college and a well known ENT centre situated in an urban area. The study period spanned over 2 years. All patients presenting with chronic ear disease who have not responded to routine antibiotic therapy were included in this study if they met inclusion criteria like presence of multiple tympanic membrane perforations and presence of pale granulation tissue in external auditory canal. In all patients detailed history was taken, including past and family history of tuberculosis. Degree of hearing loss was assessed by pure tone audiometry. Patients were screened for presence of tubercular focus elsewhere in the body (chest X-ray, montoux and ESR). Surgical intervention comprised of mastoidectomy and removal of granulation tissue. Tympanic membrane grafting was done using temporals fascia. Ossiculoplasty was done if required. Later patients were discharged on $3 \mathrm{rd}$ postoperative day and were called up for follow up and suture removal on day-8. Antitubercular treatment was started after consultation with the chest/TB physician.

Results: Total 60 patients with tubercular otitis media conforming to the inclusion criteria were included in this study. Out of these 60 patients there were 34 males (56.66\%) and 26 (43.33\%) were females with a M:F ratio of 1: 0.76. The most common age group affected was 30-40 years in males as well as females. The most common symptoms found in the studied cases were discharge from ear followed by diminished hearing and 
tinnitus. The commonest clinical finding seen in studied cases was central perforation with granulation tissue in middle ear followed by edema of external auditory canal with granulations and perforation of tympanic membrane with discharge. Preoperative hearing loss was severe in 30 patients while mild and moderate hearing loss was seen in 8 and 18 patients respectively. Profound hearing loss was seen in 4 patients. During operative procedure the most common findings observed were pale fibrotic granulation tissue, erosion of ossicular chain and mastoiditis. Postoperatively hearing was fully restored in 16 patients. While mild, moderate, severe and profound hearing loss was seen in 28, 10,4 and 2 patients.

Conclusion: Tubercular otitis media is a rare form of tuberculosis. It is usually caused by spread of infection from eustachian tube to middle ear and primary tubercular otitis media is extremely rare. Though the classical features include multiple tympanic membrane perforation, painless otorrhoea and granulation tissue in middle ear cavity it should be suspected in all patients having otitis not responding to usual antibiotics. Our study confirms that there is a definite improvement in hearing following surgical intervention and proper antitubercular therapy.

Keywords: Tuberculous otitis media, granulation tissue, Hearing loss, surgical intervention.

\section{Introduction}

India is one of the countries along with the subSaharan Africa to be having a high burden of tuberculosis ${ }^{[1]}$. The prevalence of all forms of tuberculosis in India is approximately 5 per thousand, prevalence of smear-positive cases is estimated to be around 2.25 per 1000 and annual incidence of smear-positive cases is around 85 per 1,00,000 annually ${ }^{[2]}$. The World Health Organization (WHO) statistics showed that out of global incidence of 9.6 million only India accounts for about 2.2 million cases. The estimated tuberculosis prevalence in the year 2015 was about 2.5 million $^{[3]}$. It is estimated that approximately $40 \%$ of the Indian population is infected with tubercular bacilli the majority of these people won't have any signs and symptoms of tuberculosis they rather would be silent carriers of tubercular infection ${ }^{[4]}$. This latent infection may not only be a source of infection to other susceptible individuals but also may cause disease in the individuals harboring tubercular bacilli whenever there is immunosuppression ${ }^{[5]}$. The common forms of tubercular disease include pulmonary tuberculosis, tubercular pleural effusion, tubercular lymphadenitis and tubercular meningitis (particularly in paediatric age group). The less common forms of tuberculosis include tubercular osteomyelitis, abdominal kochs and urogenital tuberculosis ${ }^{[6]}$. The incidence of disseminated and miliary tuberculosis is gradually decreasing due to widespread BCG vaccination ${ }^{[7]}$.
Tuberculous otitis media is relatively uncommon form of tuberculosis. It is characterized by painless otorrhoea and the disease poorly responds to usual antimicrobial treatment ${ }^{[8]}$. On examination tympanic membrane may show simple or multiple perforations, abundant granulation tissue and bone necrosis. Deafness is generally out of proportion to the apparent pathology. Surgery is required to remove sequestra, granulation tissue, improve drainage \& ventilation. High index of suspicion is needed for early diagnosis and prompt anti-tubercular treatment ${ }^{[9]}$. Tuberculous otitis media is usually treated with modified radical mastoidectomy. Complete uninterrupted antitubercular therapy is essential. In complicated cases like facial nerve palsy, subperiosteal abcess, mastoiditis and labyrinthitis additional specific surgical interventions may be required ${ }^{[10]}$.

\section{Materials and Methods}

The study was undertaken after the approval from institutional ethical committee. This was a multicentric prospective cohort study comprising of 60 patients who attended ENT department of a medical college and a well known ENT centre situated in an urban area. Most of the patients presented with symptoms of chronic suppurative otitis media like discharge from ear, deafness, tinnitus and earache. In all patients detailed history was taken, including past and family history of tuberculosis. Pure tone audiometry was 
done with a mean of pure tone average at 500, 1000 and $2000,3000 \mathrm{~Hz}$ to know the degree of hearing loss. Radiological and microbiological studies were done. All patients evaluated to find out primary focus especially primary pulmonary tuberculosis (CXR, ESR and montoux) but none of patients in this series was associated with pulmonary tuberculosis.

\section{Inclusion criteria}

1. Patients of chronic ear disease not responding to culture based antibiotic therapy.

2. Suspected cases showing pale granulation tissue in the external auditory canal or middle ear

3. Patients having multiple perforations.

4. Patients posted for tympanoplasty or mastoid exploration with the presence of pale granulation/polypoid tissue.

\section{Exclusion criteria-}

1. Patients with intra-cranial complications

2. Revision cases.

\section{Surgical Procedure}

Canal wall up /canal wall down mastoidectomy was done and granulation tissue was submitted to histopathological examination where in caseation necrosis, multi-nucleated giant cells and lymphatic infiltration was seen. During mastoidectomy attention was given to remove granulation tissue from all accessible mastoid air cells. Decision to perform Canal wall up /canal wall down mastoidectomy was taken depending on granulation tissue in attic and additus and status of posterior-superior canal wall. Temporalis fascia was used for tympanic membrane grafting in all patients. In few patients sliced conchal cartilage was used along with temporalis facia graft. Ossiculoplasty with autologous cartilage either from concha or tragus was also performed whenever required. Type II Ossiculoplasty was performed in patients with intact stapes and type III ossiculoplasty was done in patients with eroded stepes. In all patients gelfoam soaked with inj. dexamethasone was kept in middle ear \& external auditory canal. Patient was given mastoid bandage after surgical procedure.

\section{Discharge and follow up}

Patients without complications were discharged on post-op day 3. All patients prescribed with oral broad spectrum antibiotics and methylprednisolone for 1 week and was called for followup on $8^{\text {th }}$ day for suture removal. Once confirmed on histopathology report antitubercular therapy was started within 8-10 days of surgery. Antitubercular therapy was considered after consultation with chest physician. All the patients were followed up on 15 Day, 1 month, 3 months $\&$ then after completion of antitubercular therapy.

\section{Observations and Results}

Out of studied 60 cases of tuberculous otits media there were 34 males and 26 females with a M:F ratio of 1:0.76.

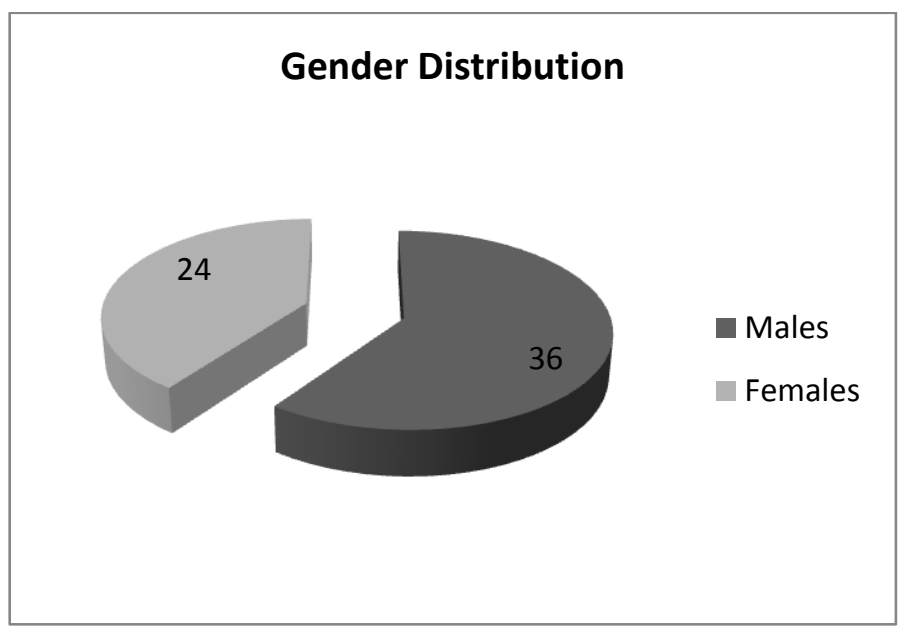

Figure 1 Gender Distribution of the studied cases.

Our study group comprised of all age group ranging from 10-60 yrs. Maximum number of patients belonged to age group of 30-40 years having 13 males and 14 females followed by 40 50 years (13/60) and 20-30 years (8/60) 


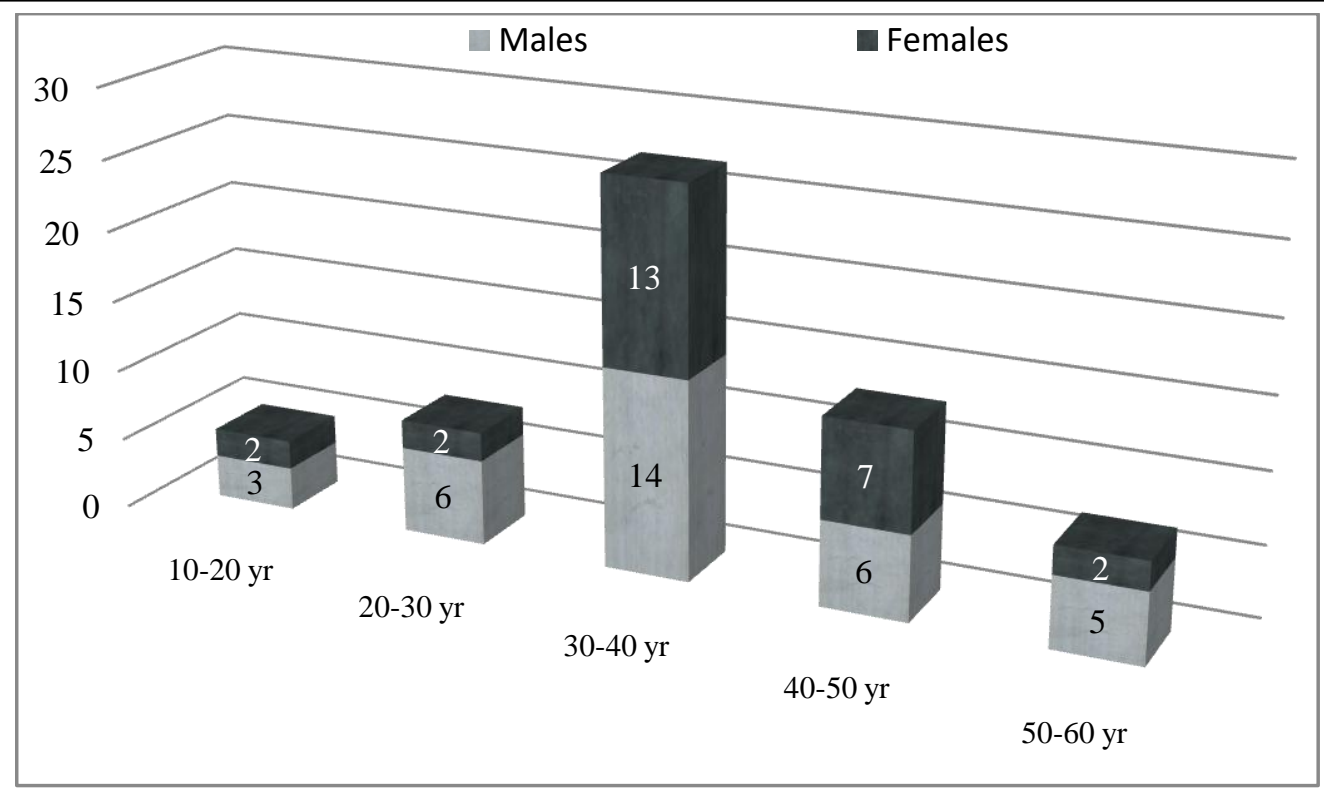

Figure 2 : Age distribution of the studied cases.

The most common presenting complaint in the studied cases was found to be discharge from ear which was seen in all 60 patients $(100 \%)$ followed by diminished hearing (91.66\%), otalgia (41.66\%) and tinnitus (33.33\%). Less common signs or symptoms seen in the studied cases were swelling around the ear (5\%), facial paralysis (3.33\%) and post-aural fistula (3.33\%).

Table 1 : Presenting complaints in the studied cases.

\begin{tabular}{cccc}
\hline $\begin{array}{c}\text { Sr. } \\
\text { No }\end{array}$ & Presenting complaints & No. Of cases & Percentage \\
\hline 1 & Ear Discharge & 60 & $100 \%$ \\
2 & Diminished hearing & 55 & $91.66 \%$ \\
3 & Tinnitus & 20 & $41.66 \%$ \\
4 & Otalgia & 25 & $33.33 \%$ \\
5 & Ataxia & 08 & $13.33 \%$ \\
6 & Facial paralysis & 02 & $3.33 \%$ \\
7 & Swelling around the ear & 03 & $5 \%$ \\
8 & Post aural fistula & 02 & $3.33 \%$ \\
\hline
\end{tabular}

The most common examination finding seen in the studied cases was found to be central perforation with presence of granulation tissue in the middle ear which was found in 24 patients (40\%) followed by oedema of external auditory canal with granulations (20\%) and perforation of tympanic membrane with discharge (16.66\%).

Table 2 : Examination findings in the studied cases

\begin{tabular}{lc|c}
\hline $\begin{array}{c}\text { Sr. } \\
\text { No }\end{array}$ & Examination findings & $\begin{array}{c}\text { No. Of } \\
\text { cases }\end{array}$ \\
\hline 1 & $\begin{array}{c}\text { Edema of Ext auditory canal with } \\
\text { granulations }\end{array}$ & 12 \\
2 & Multiple perforations & 04 \\
3 & Cp with granulations in middle ear & 24 \\
4 & Thick and dull intact tympanic \\
membrane & 05 \\
5 & Perforation of tympanic membrane \\
with discharge & 10 \\
\hline
\end{tabular}

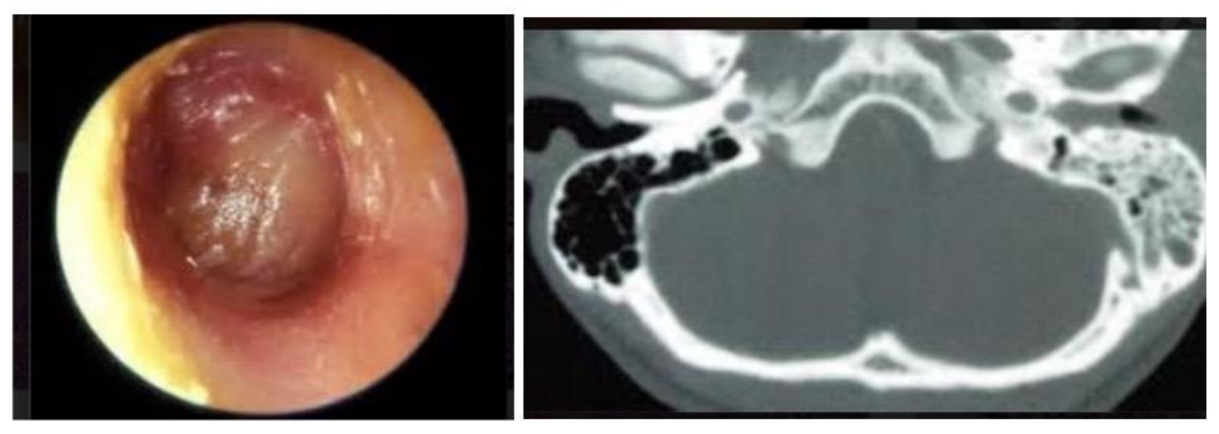

Figure 3 : Otoendoscopy showing bulging tympanic membrane with granulation tissue medial to it (Left). HRCT-Temporal bone showing granulation tissue in middle ear \& mastoid air cells (Right) 


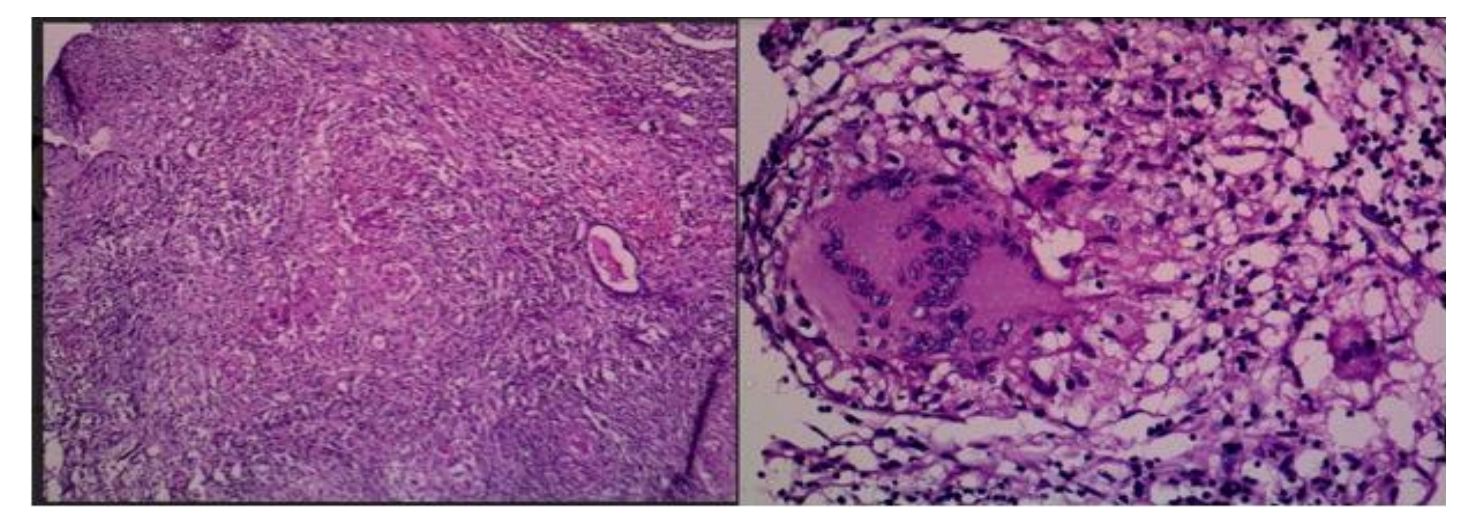

Figure 4 : H\& E staining of mastoid granulation tissue showing focal infiltration by granulomas composed of epithelioid cells, lymphocytes, histiocytes and occasional giant cells.

The analysis of hearing loss in the studied cases in preoperative period revealed that the most common type of hearing loss in these patients was mixed type (conductive +sensory) which was seen in 26 patients $(43.33 \%)$ while conductive hearing loss and sensoryneural hearing loss was seen in $22(36.66 \%)$ and $12(20 \%)$ patients respectively. $50 \%$ of the patients $(30 / 60)$ suffered from severe hearing loss followed by moderate $(30 \%)$ and mild (13.33\%) types of hearing loss.

Table 3 : Pre-operative hearing loss (pure tone average $=56.8 \mathrm{db}$ ) in studied cases

\begin{tabular}{lcccc}
\hline Seviarity of hearing loss & No. Of cases & \multicolumn{3}{c}{ Type of hearing loss } \\
\hline & & CHL & MHL & SNHL \\
Mild & 8 & 2 & 4 & 2 \\
Modreate & 18 & 12 & 6 & -- \\
Severe & 30 & 8 & 16 & 6 \\
Profound & 4 & -- & -- & 4 \\
Total & 60 & 22 & 26 & 12 \\
\hline
\end{tabular}

Post-operatively there was remarkable profoundly affected despite surgical intervention. improvement in the hearing of the studied cases . 16 patients had normal hearing while mild, moderate and severe hearing loss still persisted in 28,10 and 4 patinents. 6 patients remained Profound deafness persisted in patients of sensoryneural hearing loss making making these patients a group less likely to regain hearing despite surgical interventions.

Table 4 : Post-operative hearing loss (pure tone average $=41.2 \mathrm{db}$ ) in the studied cases

\begin{tabular}{lcccc}
\hline Seviarity of hearing loss & No. Of cases & \multicolumn{3}{c|}{ Type of hearing loss } \\
\cline { 3 - 5 } & & CHL & MHL & SNHL \\
Normal hearing & 16 & -- & -- & -- \\
Mild & 28 & 14 & 12 & 2 \\
Modrate & 10 & -- & 10 & -- \\
Severe & 4 & -- & 2 & 2 \\
Profound & 2 & -- & -- & 2 \\
Total & 60 & 14 & 24 & 6 \\
\hline
\end{tabular}

Most common intra-operative finding in the studied cases was found to be pale fibrotic granulation tissue which was seen in all the cases. Other findings which were seen during operative interventions were lateral canal fistula, mastoid abscess, glue ear and mastoid fistula. 
Table 5 Intra-operative findings in the studied cases.

\begin{tabular}{|c|c|c|}
\hline $\begin{array}{l}\text { Sr. } \\
\text { No }\end{array}$ & Intra-operative findings & $\begin{array}{l}\text { No. Of } \\
\text { cases }\end{array}$ \\
\hline 1 & Canal wall up mastoidectomy & 18 \\
\hline 2 & Canal wall down mastoidectomy & 40 \\
\hline 3 & Pale fibrotic granulation tissue & 60 \\
\hline 4 & Fallopian canal erosion & 2 \\
\hline 5 & Lateral canal (labyrinthine) fistula & 2 \\
\hline 6 & Mastoid abscess & 1 \\
\hline 7 & Mastoid fistula & 1 \\
\hline 8 & Glue & 8 \\
\hline 9 & Erosion of maleous/incus/stapies & $4 / 17 / 7$ \\
\hline 10 & Erosion of dural/sinus plate & $2 / 1$ \\
\hline
\end{tabular}

\section{Discussion}

Tuberculosis is an endemic disease in developing countries including India. It is unique in the sense that the mankind is struggling to fight it sense ancient ages ${ }^{[11]}$. Despite advances in medical science and availability of novel antitubercular drugs this menace is spreading and it is still amongst the top 10 killer infectious diseases only second to HIV ${ }^{[12]}$. Human tuberculosis is caused by a group of related bacteria called Mycobacterium Tuberculosis complex (MTC). The leading type of MTC causing disease in human beings is mycobacterium tuberculosis though occasionally in some instances the infection may be caused by mycobacterium Bovis, Mycobacterium microti and mycobacterium Kansasii and mycobacterium fortuitum ${ }^{[13]}$.

The usual infection caused by mycobacterium tuberculosis is pulmonary kochs. It is one of the leading cause of symptomatic respiratory disease in developing countries. Mode of transmission is usually by droplet infection. Common signs and symptoms include cough, fever, malaise and heaemoptysis ${ }^{[14]}$. Investigations like positive montoux test, elevated ESR and imaging features may aide in the diagnosis. Acid fast bacilli in sputum are confirmatory of the diagnosis and treatment depends upon the site and severity of infection. MDR (Multi drug resistant) and XDR (extended drug resistant) tuberculosis pose a dilemma for treating physician ${ }^{[15]}$. In these cases the treatment is individualised and multiple drugs for extended periods and surgical interventions like pneumonectomy may have to be done. Other forms of tuberculosis which may be encountered in patients include tubercular meningitis (common in children), scrofuloderma, abdominal and urogenital tuberculosis, and tubercular lymphadenitis tubercular otitis media ${ }^{[16]}$.

The history of tubercular otitis media is interesting. It was (Tuberculosis of temporal bone) first described by Jean Louis Petit in 18th century ${ }^{[17]}$. In 1853 Wilde described otitis media which was characterized by painless, insidious onset otorrhoea, multiple perforations in the tympanic membrane and presence of pale granulation tissue in the middle ear ${ }^{[18]}$. One of the greatest otologist of 19th century politzer who described otosclerosis, secretory otitis media, labyrinthitis, congenital deafness, intracranial complications of otitis, and atelectasis of the ear for the first time also describe the clinical features of tuberculous otitis media fairly accurately in $1882^{[19]}$. It is only 1 decade after politzer described the features of tuberculous otitis media that the legendary microbiologist Robert koch demonstrated mycobacterium tuberculosis ${ }^{[20]}$. Primary tuberculosis of the ear is very rare. Tuberculous otitis media is usually caused by transmission of infection through eustachian tubes secondary to pulmonary tuberculosis. The condition usually begins as an apparent serous otitis media only to run an indolent course not responding to usual antibiotics ${ }^{[21]}$.

Tuberculosis of the middle ear is characterized by painless otorrhoea. It is more commonly seen in paediatric age group though no age is exempt ${ }^{[22]}$. The incidence has decreased significantly after the advent of antitubercular treatment. Otoscopic examination may show perforated tympanic membrane (multiple perforations which may later coalesce to form a single perforation is the hallmark feature) with watery discharge from it. The middle Pale middle ear mucosa with abundant pale granulations is characteristic of tuberculous otitis media ${ }^{[23]}$. This granulation may be seen in middle ear during otoscopy. During mastoid surgery they be seen in mastoid cavity. Various 
complications which can be seen in patients with tubercular otits media include facial $n$ palsy, deafness and subperiosteal abscess ${ }^{[24]}$. Treatment usually consists of antitubercular treatment, surgical explorations and mastoidectomy is frequently required in these patients. Tympanoplasty and ossicular chain repair may have to be carried out in patients with conductive deafness secondary to tubercular otitis media ${ }^{[25]}$.

In our patients we gave antitubercular treatment with combination AKT for 9 months for all patients. Few patients needed levofloxacin and oral methylprednisolone to make mastoid cavity dry. In our study we found that with proper antitubercular treatment, healing mechanism was found similar to that of non-tuberculous otitis media. There was no formation of post-aural fistula. A mean follow up of 1 year was done and all patients were found doing well except 2 occasionally discharging mastoid cavity and 1 residual perforation.

\section{Conclusion}

Tubercular otitis media is a rare form of otitis. It usually presents with painless ear discharge, multiple tympanic membrane perforations and presence of pale granulation tissue in middle ear cavity. Classical features may not be present in all the cases and a high index of suspicion is needed on the part of treating ENT surgeon to prevent complications like deafness and facial nerve paralysis. Prompt treatment will definitely improve the hearing and prevent further complication.

\section{References}

1. Sandhu GK. Tuberculosis: Current Situation, Challenges and Overview of its Control Programs in India. Journal of Global Infectious Diseases. 2011;3(2):143150.

2. World Health Organization Global tuberculosis control: surveillance, planning, financing. WHO report, 2005. Geneva: The Organization; 2005
3. Raviglione M, Sulis G. Tuberculosis 2015: Burden, Challenges and Strategy for Control and Elimination. Infectious Disease Reports. 2016;8(2):6570.

4. Robinson G. "Carriers" of Tuberculosis. British Medical Journal. 1941;2(4200):33.

5. Millar JW, Horne NW. Tuberculosis in immunosuppressed patients. Lancet. 1979 Jun 2;1 (8127):1176-8.

6. Wang JY, Hsueh PR, Wang SK, Jan IS, Lee LN, Liaw YS, Yang PC, Luh KT. disseminated tuberculosis: a 10-year experience in a medical center. Medicine (Baltimore). 2007 Jan;86(1):39-46.

7. Pereira SM, Dantas OM, Ximenes R, Barreto ML. [BCG vaccine against tuberculosis: its protective effect and vaccination policies]. Rev Saude Publica. 2007 Sep;41 Suppl 1:59-66. Review. Portuguese.

8. Mondal SK, Alam MM. Tuberculous otitis media. Mymensingh Med J. 2011 Apr;20(2):343-8.

9. Vital V, Printza A, Zaraboukas T. Tuberculous otitis media: a difficult diagnosis and report of four cases. Pathol Res Pract. 2002;198(1):31-5.

10. Hwang GH, Jung JY, Yum G, Choi J. Tuberculous Otitis Media with Facial Paralysis Combined with Labyrinthitis. Korean Journal of Audiology. 2013;17(1):27-29.

11. Eddy JJ. The ancient city of Rome, its empire, and the spread of tuberculosis in Europe. Tuberculosis (Edinb). 2015 Jun;95 Suppl 1:S23-8.

12. Bloom BR, Murray CJ. Tuberculosis: commentary on a reemergent killer. Science. 1992 Aug 21;257(5073):1055-64.

13. Johnston JC, Chiang L, Elwood K. Mycobacterium kansasii. Microbiol Spectr. 2017 Jan;5(1).

14. Ismail Y. Pulmonary tuberculosis--a review of clinical features and diagnosis in 
232 cases. Med J Malaysia. 2004 Mar;59(1):56-64. patients. Laryngoscope. 1980 Jun;90(6 Pt 1):1039-44.

15. Pontali E, Matteelli A, Migliori GB. Drugresistant tuberculosis. Curr Opin Pulm Med. 2013 May;19(3):266-72.

16. Carrol ED, Clark JE, Cant AJ. Nonpulmonary tuberculosis. Paediatr Respir Rev. 2001 Jun;2(2):113-9.

17. Petit J-L. Nouvéedition. Paris: 1790. Traité des maladies chirurgicales, et des operations qui leur conviennent.

18. Bento RF, Fonseca AC de O. A brief history of mastoidectomy. International Archives of Otorhinolaryngology. 2013;17(2):168-178.

19. Diamant H, Hultcrantz M. [Glimpses from the history of otitis media]. Nord Medicinhist Arsb. 1996:189-95. Swedish.

20. Sakula A. Robert Koch: Centenary of the Discovery of the Tubercle Bacillus, 1882. The Canadian Veterinary Journal. 1983;24(4):127-131.

21. Kameswaran M, Natarajan K, Parthiban M, Krishnan PV, Raghunandhan S.Tuberculous otitis media: a resurgence? J Laryngol Otol. 2017 Jul 20:1-8.

22. Manigandan G, Venkatesh C, Gunasekaran D, Soundararajan P. Tuberculous Otitis Media and Staphylococcus aureus Coinfection in a Five-Year-Old Boy with Miliary Tuberculosis. Journal of Global Infectious Diseases. 2013;5(1):26-28.

23. Abes GT, Abes FL, Jamir JC. The variable clinical presentation of tuberculosis otitis media and the importance of early detection. Otol Neurotol. 2011 Jun;32(4):539-43.

24. Prakash M, Johnny JC. Intra cranial complications of tuberculous otitis media. Journal of Pharmacy \& Bioallied Sciences. 2015;7(Suppl 1):S51-S54.

25. Windle-Taylor PC, Bailey CM. Tuberculous otitis media: a series of 22 